\title{
Electric Field Prediction using Micro-plasma Inside Microwave Cavity for Soot Oxidation
}

\author{
Haitham B. Al-Wakeel ${ }^{1, a}$, Zainal Ambri Abdul Karim ${ }^{1}$, Hussain H. Al-Kayiem ${ }^{1}$ \\ ${ }^{1}$ Mechanical Engineering Department, University Technology PETRONAS, Bandar Seri Iskandar, \\ 31750 Tronoh, Perak, Malaysia
}

\begin{abstract}
The reduction of the harmful emission soot is necessary in recent years due to the environmental protection regulation. Soot is a carbonaceous matter and a strong absorber of microwave energy. Microwave heating offers the advantage over conventional heating to oxide soot. Where plasma is high electric field that leads to instantaneous temperature rising. This paper proposes a recent concept for soot oxidation using micro-plasma in a microwave cavity. The concept was presented by simulating the electric field using microwave heating and thin metal object. Five cases were examined numerically in a mono-mode $\mathrm{TE}_{10}$ microwave cavity WR430 having closed surfaces of perfect electric conductors working under $2.45 \mathrm{GHz}$ frequency and $1500 \mathrm{~W}$ power supply to predict the electric field and dissipated heat distribution. The methodology of prediction was implemented using ANSYS based on FEM. The present prediction results showed higher electric field $(400 \mathrm{kV} / \mathrm{m})$ and high dissipated heat $\left(3.7 \times 10^{10} \mathrm{~W} / \mathrm{m}^{3}\right)$ can be obtained for a soot sample backed with metal rods inserted vertically with gaps not exceeding $1.5 \mathrm{~mm}$ between the rods tips. Also increasing the number of metal rods, from 8 to 14 increases the maximum value of electric field formed in the soot sample to 575 $\mathrm{kV} / \mathrm{m}$. The simulation results revealed the ability of achieving high electric field by using microwave heating with the assistance of metal objects.
\end{abstract}

\section{Introduction}

Soot is a fine black particle, chiefly composed of carbon, formed through incomplete combustion of coal, oil, wood, and other fuels. Soot causes significant harms to public health, particularly because of its very small size, that it can easily enter the lungs and bloodstream, potentially causing damage in a number of ways. Breathing of this particle can potentially cause cancer. Soot causes several environmental problems, such as decreasing the range of visibility and haze. Haze is formed when sunlight interacts with small particles in the atmosphere. So soot emission reduction will be required from vehicles, power plants, and stationary diesel engines. The various methods that were used to reduce the emission of soot were mentioned in [1]. The electromagnetic wave in a mono-mode microwave cavity was numerically analyzed by [2]. Their results showed that the electric field varied with dielectric material properties and position in a microwave cavity. Next many simulations were conducted to find the electric field and temperature distribution on dielectric materials by using microwave heating [3-7]. The findings indicated that electromagnetic energy was absorbed by the dielectric material and dissipated as heat energy leading to increase in the material temperature. The

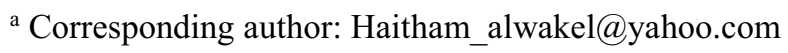

This is an Open Access article distributed under the terms of the Creative Commons Attribution License 2.0, which permits unrestricted use, distribution, and reproduction in any medium, provided the original work is properly cited. 
absorbed energy depends on dielectric properties and electric field formed from electromagnetic wave-material interactions. More findings were reported in [8]. Theoretical and experimental researches were conducted on materials mixed with metal powder for material sintering as in [9-10]. The finding showed that high electric field and high temperature without spark were formed in dielectric material. Shukla et al. [11] numerically modeled susceptor-assisted microwave heating. The model result reveals the maximum temperature increase by using susceptor and the efficiency of microwave heating depends on the sample size and thermal conductivity. Shayeganrad et al. [12] found experimentally that thick metal objects in a microwave oven reflect the microwave. While thin metal generates electric current on the metal surface forming with the microwave frequency a high electric field at the objects tips. It is quite clear that the literature in the field using micro-plasma for soot oxidation is unavailable.

This paper presents a simulation of a new method for rapid and direct treatment of soot using microwave heating and metal thin rods post inside a microwave cavity to obtain high electric field and dissipated heat. Five simulation cases were conducted using ANSYS based on finite element method (FEM) to investigate electric field and electromagnetic power absorption formed due to electromagnetic wave - soot interaction - metal assisted in a mono-mode $\mathrm{TE}_{10}$ microwave cavity WR430.

\section{Theory}

The governing equations of the electric field of electromagnetic energy and dissipated heat in a microwave cavity is described in the following

The equation of electric field, $(\boldsymbol{E})[13,14]$ is

$$
\begin{gathered}
\boldsymbol{E}=E_{0} e^{-\gamma^{2} x y z} \\
\gamma^{2}=-\omega^{2} \mu_{0} \mu_{r} \varepsilon_{0} \varepsilon_{r}^{\prime}\left[1-j\left(\frac{\varepsilon_{r}^{\prime \prime}}{\varepsilon_{r}^{\prime}}+\frac{\sigma}{\omega \varepsilon_{0} \varepsilon_{r}^{\prime}}\right)\right]
\end{gathered}
$$

The equation of absorbed electromagnetic energy $\left(P_{a b c}\right)$ or dissipated heat $(J H E A T)$ is $[3,14]$

$$
P_{a b s}=\operatorname{JHEAT}=\left(\frac{1}{2}\right) \omega \varepsilon_{0}\left(\varepsilon_{r}{ }^{\prime}+\frac{\sigma}{\omega \varepsilon_{0}}\right)|E|^{2}
$$

The generator equation is [14]

$$
v=\int_{0}^{l} \boldsymbol{E} \cdot d l=|\boldsymbol{E}| \cos \theta L
$$

\section{Numerical analyses}

The simulation was conducted by using finite element method (FEM) edge based of ANSYS software to find the electric field distribution and dissipated heat in soot contained metal rods. Soot and rods were posted inside a mono-mode $\mathrm{TE}_{10}$ microwave cavity WR430 [3]. The cavity is a block with dimensions, $a=0.10922 \mathrm{~m}$ on $x$-axis, $b=0.056 \mathrm{~m}$ on $y$-axis, and $d=0.14772 \mathrm{~m}$ on $z$-axis. The cavity surfaces are perfect electric conductors. The operating frequency is $2.45 \mathrm{GHz}$ and power supply is $1500 \mathrm{~W}$. The dimensions of cylindrical specimen (soot) are given in Table 1. The metal rods are cylindrical shape having diameter equal to $0.0005 \mathrm{~m}$ with $0.0015 \mathrm{~m}$ gap between the rods tips. The program inputs were relative dielectric properties of air, soot and metal rods. The electric field and electromagnetic absorbed energy that were formed from the interaction of electromagnetic wave with metal and dielectric material were found by program using equations 1 and 3 . 


\section{Results and discussion}

For the purpose of soot oxidation strategy five simulation cases were conducted to obtain maximum $\boldsymbol{E}$ formed by high frequency electromagnetic wave and rods post in a mono-mode microwave cavity WR430. The simulations results are summarized in table 1 .

Table 1. Results of simulation cases

\begin{tabular}{|c|c|c|c|c|c|c|c|c|}
\hline $\begin{array}{l}\text { Case } \\
\text { No. }\end{array}$ & Case description & $\begin{array}{c}\text { Soot } \\
\text { diameter } \\
\text { (m) }\end{array}$ & $\begin{array}{l}\text { Soot } \\
\text { length } \\
\text { (m) }\end{array}$ & $\begin{array}{c}\text { Number } \\
\text { of rods }\end{array}$ & $\begin{array}{l}\text { Length } \\
\text { of rods } \\
\text { (m) }\end{array}$ & $\begin{array}{c}\text { Max. Esum } \\
(\mathbf{V} / \mathbf{m}) \text { approx. }\end{array}$ & $\begin{array}{l}\text { JHEAT } \\
\left(\mathrm{W} / \mathbf{m}^{3}\right) \\
\text { approx. }\end{array}$ & $\begin{array}{l}\text { Figure } \\
\text { No. }\end{array}$ \\
\hline 1 & $\begin{array}{l}\text { Horizontal sample cylinder } \\
+ \text { vertical rods }\end{array}$ & 0.038 & 0.1092 & 8 & 0.0125 & 250000 & $1.0 \times 10^{10}$ & 1 \\
\hline 2 & $\begin{array}{l}\text { Vertical sample cylinder }+ \\
\text { horizontal rods }\end{array}$ & 0.038 & 0.0561 & 8 & 0.0125 & 5000 & $1.0 \times 10^{6}$ & 2 \\
\hline 3 & $\begin{array}{l}\text { Vertical sample cylinder }+ \\
\text { vertical rods (side view) }\end{array}$ & 0.038 & 0.0561 & 8 & 0.0125 & 400000 & $3.7 \times 10^{10}$ & 3 \\
\hline 4 & $\begin{array}{l}\text { Vertical sample cylinder }+ \\
\text { vertical rods (front view) }\end{array}$ & 0.038 & 0.0561 & 8 & 0.0125 & 350000 & $2.7 \times 10^{10}$ & 4 \\
\hline 5 & $\begin{array}{l}\text { Vertical sample cylinder }+ \\
\text { vertical rods }\end{array}$ & 0.018 & 0.0561 & 14 & 0.006 & 575000 & $4.0 \times 10^{10}$ & 5 \\
\hline
\end{tabular}

Case 1 reveals the maximum value of $\boldsymbol{E}$ is $250 \mathrm{kV} / \mathrm{m}$ (red color in Fig. 1b) formed inside a soot sample laid horizontally inside a microwave cavity and the eight spiky rods post vertically, with 1.5 $\mathrm{mm}$ gap between the tips (figure 1a). Case 2 shows the opposite position for both sample and rods (figures $2 \mathrm{a}$ and $2 \mathrm{~b})$. The value of maximum $\boldsymbol{E}(5 \mathrm{kV} / \mathrm{m})$ is lower than case 1 (blue color in figure $2 \mathrm{c}$ ). Cases 3 and 4 give the maximum $\boldsymbol{E}$ equal to $(350-400) \mathrm{kV} / \mathrm{m}$ (red color in figures $3 \mathrm{~b}$ and 4 ) when the sample and rods were placed vertically inside the cavity as shown in figure $3 \mathrm{a}$. The reason of this phenomena is $\boldsymbol{E}$ in a resonant microwave cavity have only one component in vertical direction $(\boldsymbol{E y})$ and the value of other components $(\boldsymbol{E x}, \boldsymbol{E} \boldsymbol{z})$ are set to zero [8]. The value of $\boldsymbol{E} \boldsymbol{y}$ is constant vertically along the $y$ axis in the sample and decreases horizontally heading to the sides on $x$ axis. Therefore, it is important that the sample and rods are grouped vertically parallel to $\boldsymbol{E} \boldsymbol{y}$ according to equation 4. Case 5 was introduced to increase the maximum value of $\boldsymbol{E}$ in the center of the sample by increasing the number of rods to 14 with $1.5 \mathrm{~mm}$ gaps between the rods tips at the sample center where the maximum $\boldsymbol{E}$ attained to $575 \mathrm{kV} / \mathrm{m}$ (red color in figures 5 a and $5 \mathrm{~b}$ ). The value of $\boldsymbol{E}$ in case 5 was increased due to the positive interaction between the electric fields that were formed around the rods tips. It is noticed from table 1, the value of generated heart (JHEAT) depends on $\boldsymbol{E}$ and its value increases with $\boldsymbol{E}$ increasing according to equation 3.

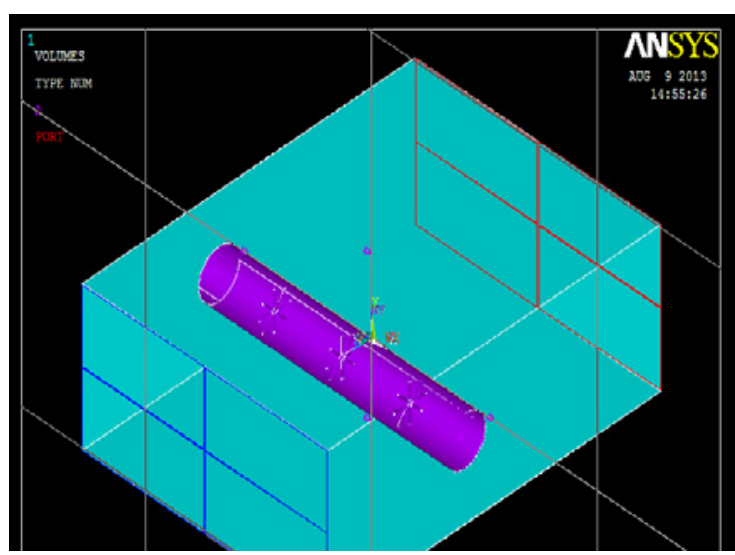

Figure 1a. Cavity include soot sample and rods of case 1

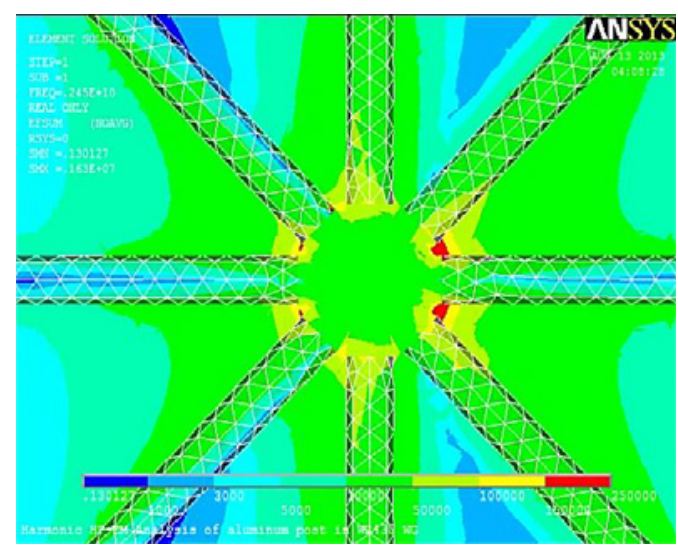

Figure 1b. Side view on the center of the sample, case 1 


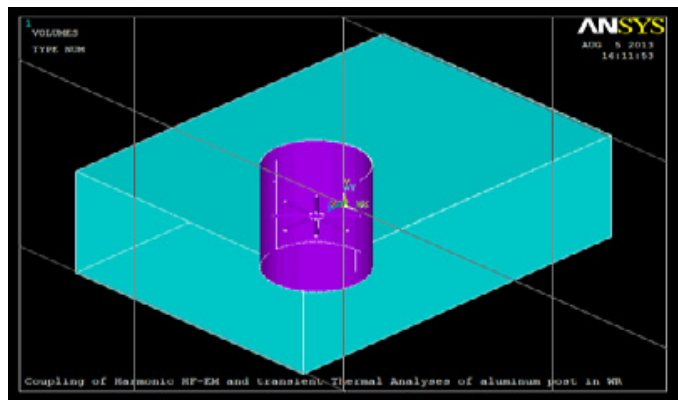

Figure 2a. Cavity included soot sample and rods, case 2

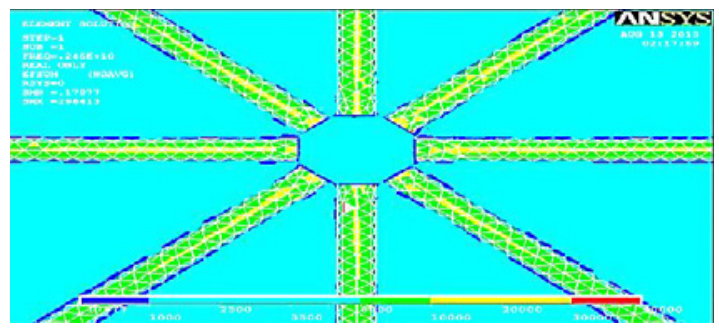

Figure 2c. Top view on the center of sample, cas2

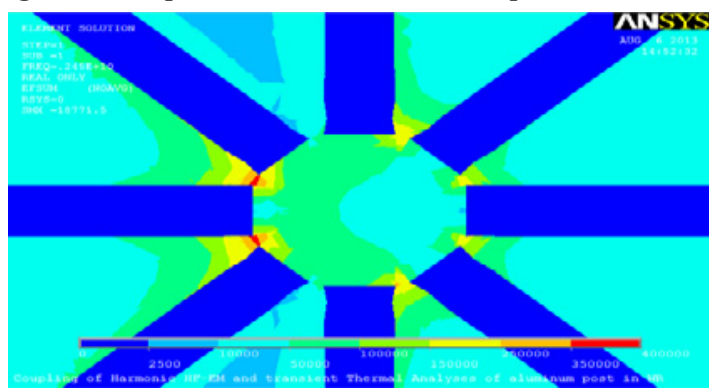

Figure 3b. Side view on the sample center, case 3

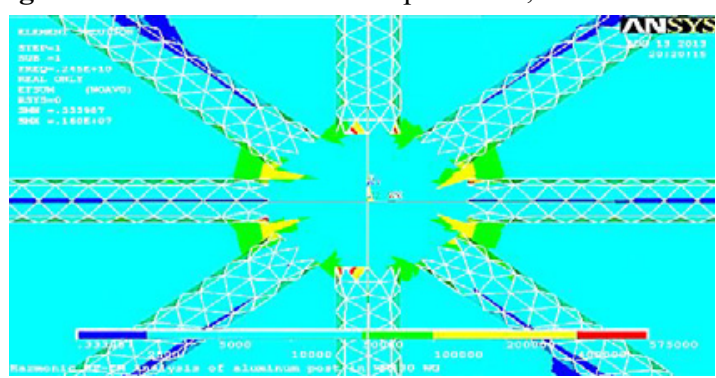

Figure 5a. Front view on the sample center, case 5

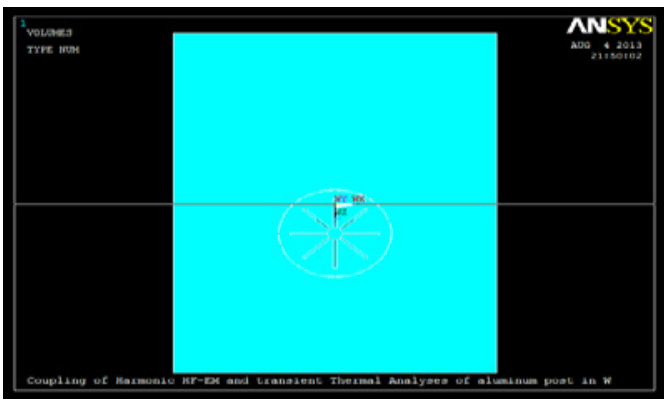

Figure 2b. Top view for cavity, case 2

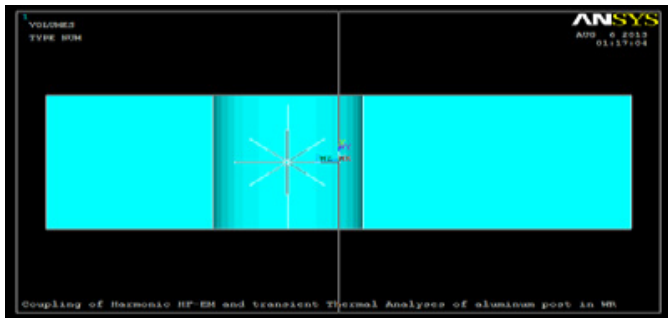

Figure 3a. Vertical sample and rods in a cavity,case3

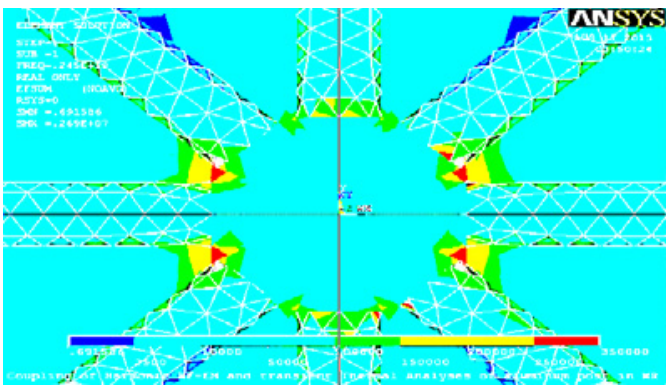

Figure 4. Front view on the sample center, case 4

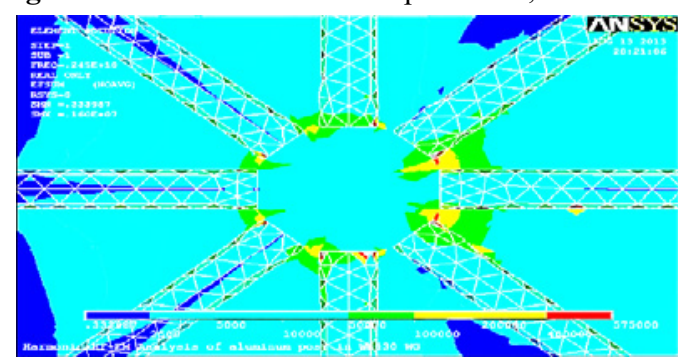

Figure 5b. Side view on the sample center, case 5

\section{Conclusions and Further Development}

In this work a new concept to simulate highest electric field during the microwave heating using thin metal objects or micro-plasma inside a microwave cavity. Five study cases were examined numerically to simulate the electric field and dissipated heat distribution. The cases are segregated according to the arrangement of the samples and metal rods inside the cavity. The findings from the results are:

- High electric field $(400 \mathrm{kV} / \mathrm{m})$ and dissipated heat $\left(3.7 \times 10^{10} \mathrm{~W} / \mathrm{m}^{3}\right)$ obtained by post the soot sample and 8 metal rods vertically and leave $1.5 \mathrm{~mm}$ gaps between the rods tips. 
- Increasing the number of metal rods to 14 leads to increase the maximum value of electric field formed in the soot sample to $(575 \mathrm{kV} / \mathrm{m})$ and dissipated heat to $\left(4 \times 10^{10} \mathrm{~W} / \mathrm{m}^{3}\right)$.

For further development, the experimental work and the simulation of the temperature distribution and soot reduction would be required to improve the understanding of the phenomena.

\section{Nomenclature}

\begin{tabular}{|ll|ll|}
\hline$d l$ & length integral & $\varepsilon_{r^{\prime}}$ & Relative dielectric constant \\
$\boldsymbol{E}$ & Electric field intensity vector & $\varepsilon_{r}{ }^{\prime}$ & Relative dielectric loss factor \\
$E_{0}$ & Amplitude of electric field intensity & $\theta$ & Angle between conductor and $\boldsymbol{E}$ \\
$j$ & Complex number & $\mu$ & Magnetic permeability \\
$L$ & Conductor length & $\mu_{0}$ & permeability of vacuum or air \\
$P_{a b s}$ & Absorbed power & $\mu_{r}$ & Relative permeability \\
$\gamma$ & Complex propagation constant & $\sigma$ & Electric conductivity \\
$\varepsilon$ & Complex Permittivity & $v$ & Emf between two points on \\
$\varepsilon_{0}$ & Permittivity of vacuum or air & $\omega$ & Angular frequency \\
\hline
\end{tabular}

\section{Acknowledgement}

The authors would like to acknowledge Universiti Teknologi PETRONAS for the financial support which was received through the Exploratory Research Grant from Ministry of Higher Education.

\section{References}

[1] H. B. Al-Wakeel, Z. A. Abdul Karim, H. H. Al-Kayiem, Journal of Applied Science, 12, 23 (2012) 2338-2345.

[2] S. Tada, R. Echigo, H. Yoshid, Journal of Heat and Mass Transfer, 41, 4-5 (1998) 709-718.

[3] T. V. Chow Ting Chan, H. C. Reader, Understanding microwave heating cavities, Artech House Inc., London, 2000.

[4] K.-M. Huang, Z. Lin, X.-Q. Yang, Progress In Electromagnetics Research, 49 (2004) 273-289.

[5] N. Makul, P. Keangin, P. Rattanadecho, B. Chatveera, D. K. Agrawal, Journal of International Communications in Heat and Mass Transfer, 37 (2010) 1096-1105.

[6] T. Ciacci, A. Galgano, C. Di Blasi, Journal of Chemical Engineering Science, 65 (2010) 41174133.

[7] D. Salvi, D. Bolder, J. Ortgo, G. M. Aita, C. Sabliov, Journal of Microwave Power and Electromagnetic Energy, 44, 4 (2010) 187-197.

[8] H. B. Al-Wakeel, Z. A. Abdul Karim, H. H. Al-Kayiem, H. Fawad, Applied Mechanics and Materials 459 (2014) 310-318.

[9] M. Gupta, E. Wong Wai. Leong, Microwaves and metals, Wiley, Singapore, (2007).

[10] J. Cheng, R. Roy, D. Agrawal, Journal of Materials Science Letters, 20 (2001) 1561-1563.

[11] A. K. Shukla, A. Mondal, A. Upadhyaya, 42 (2010) 99-124.

[12] G. Shayeganrad, L. Mashhadi, Proceedings of Progress in Electromagnetics Research Symposium, Beijing, China, (2009).

[13] J. Jin, The Finite element method in electromagnetics, second ed., Wiley, New York, (2002).

[14] J. D. Kraus, D. A. Fleisch, Electomagnetics with applications, fifth ed., McGraw Hill, Singapore, (1999). 